\title{
Neonatal Borna disease virus infection in the rat causes a loss of Purkinje cells in the cerebellum
}

\author{
Leonard M Eisenman ${ }^{1}$, Rachel Brothers ${ }^{1}$, Man H Tran ${ }^{1}$, Rhonda B Kean², Gregory M Dickson², \\ Bernhard Dietzschold ${ }^{2}$ and D Craig Hooper ${ }^{2}$ \\ Departments of ${ }^{1}$ Pathology, Anatomy and Cell Biology, and ${ }^{2}$ Microbiology and Immunology, Jefferson Medical College, \\ Thomas Jefferson University, Philadelphia, Pennsylvania 19107, USA
}

\begin{abstract}
Viral insults that occur during early postnatal periods, can affect neuronal systems which exhibit significant postnatal development, such as the cerebral cortex and cerebellum. Borna disease virus (BDV) is a single-strand RNA virus which replicates in the nervous system of many species after experimental inoculation and causes acute neurological disease. Neonatal rats infected with BDV do not mount an aggressive response to the virus like their adult counterparts, but instead develop a persistent BDV infection with less overt clinical sequelae. Recently, the cerebellum, a neural structure associated with regulation of motor behavior, and perhaps with higher cognitive functions, has been demonstrated to be a target of neonatal BDV infections in rats (Bautista $e t$ $a l, 1995)$. In the present study neonatal rats were infected with BDV and their cerebella were analyzed histologically and immunohistochemically at 7 months of age. The cerebella of infected animals were reduced in size but normal foliation and laminar organization was present. However, as visualized with immunohistochemistry for the Purkinje cell-specific antigen calbindin, there were numerous gaps within the Purkinje cell layer and in the molecular layer which contains the Purkinje cell dendritic trees. We estimated the number of Purkinje cells and found there was an approximately $75 \%$ loss of PC in adult rats neonatally infected with BDV. These results suggest that neonatal BDV infection may either (1) target the PC and cause the death of these cells directly or (2) acts indirectly by triggering an immune response which is then responsible for the loss of these cells.
\end{abstract}

Keywords: immune system; neurodegenerative; tolerance; immunohistochemistry

\section{Introduction}

Viral infections frequently target the nervous system and cause neurodegenerative and neurobehavioural consequences. Infections which occur during embryogenesis can cause congenital malformations of the central nervous system (Oakley et al, 1986; Seay and Griffin, 1981). Viral insults which occur during early postnatal development can affect neuronal systems which exhibit significant postnatal development, such as the cerebral cortex and the cerebellum. These malformations can manifest themselves as subtle alterations of cell genesis, migration, differentiation and connectivity. Although not visibly obvious, such malformations can have important consequences on the function of the nervous system. They may lead to altered neuronal irritability, decreased learning and mem-

Correspondence: LM Eisenman

Received 23 June 1998; revised 18 September 1998; accepted 22 September 1998 ory capabilities, and emotional and motivational abnormalities expressed as neuropsychiatric disorders.

Borna disease virus (BDV) is a single-strand RNA virus which replicates in the nervous system of many species after experimental inoculation (Carbone et al, 1987; de la Torre et al, 1990; Lipkin et al, 1990) and causes acute neurologic disease which, evidently, is somewhat variable in its outcome at least partly due to the strain of BDV used. The manifestations of the infection, which is often lethal, are typically characterized by ataxia, hyperactivity and aggressive behavior. Extensive studies, primarily in the rat, have revealed that the severe, acute Borna disease seen in immunocompetent adult rats as well as other laboratory animals and in the natural infection of horses and sheep, is likely to be the result of an aggressive immune response to the virus rather than the virus infection itself (Richt et al, 1990; Rott et al, 1988; Stitz et al, 1995). Thus, 
rats made immunologically tolerant of BDV antigens or treated with immunosuppressive therapy do not develop acute Borna disease (Carbone et al, 1991; Morimoto et al, 1996; Narayan et al, 1983; Stitz et al, 1989). During the perinatal period the rat immune system is not fully mature and contact with antigen often leads to immunological tolerance of that antigen (Billingham et al, 1953; Burtles and Hooper, 1990). Neonatal rats infected with BDV do not mount an aggressive response to the virus like their adult counterparts, but instead develop a persistent BDV infection with less overt clinical sequelae (Carbone et al, 1987).

The detection of antibodies to BDV in sera of patients with major affective illness (Amsterdam et al, 1985; Bechter et al, 1992; Bode et al, 1988; Rott et al, 1985, 1991; VandeWound et al, 1990; Waltrip et al, 1995) has led to attempts to identify BDV in human psychiatric patients. The results of these studies are highly controversial in either identifying or failing to detect evidence of BDV infection in peripheral blood cells and brain tissue from psychiatric patients (Bode et al, 1995; Kishi et al, 1995a,b; Richt et al, 1990). Evidence supporting this notion of an association between BDV and psychiatric illness also comes from studies which show disturbances in the catecholamine system in rats infected with BDV (Solbrig et al, 1996a, b). The possibility that a covert neurotropic BDV infection may contribute to human psychiatric disease emphasizes the importance of understanding the relationship between the virus and its host in models where severe disease does not occur, such as in rats infected with BDV at birth.

Recently, the cerebellum, a neural structure associated with regulation of motor behavior, has been demonstrated to be a target of neonatal BDV infections in rats (Bautista et al, 1995). In addition to motor control, the cerebellum has also been implicated in higher cognitive functions (BrackeTolkmitt et al, 1989; Daum et al, 1993; Leiner et al, 1989). In particular, perceptual timing tasks have been shown to be impaired in patients with cerebellar lesions (Ivry and Keele, 1989). This neuronal structure exhibits significant postnatal development, and has been shown to be a target of neonatal viral infections such as lymphocytic choriomeningitis virus (LCMV), rat parvovirus and reovirus (Margolis et al, 1971; Monjan et al, 1971, 1973; Oster-Granite and Herndon, 1986; Raine and Fields, 1973). Neonatal infection with BDV in Lewis rats has been reported to result in a premature loss of the external granule cell layer (egl), the germative layer for the production of granule cells which populate the internal granule cell layer (igl). In addition, there was a reduced cerebellar size reported. Even though infected granule cells were not detected, the reduced cerebellar size was attributed to a signifiant loss of granule cells (Bautista et al, 1995). Purkinje cells were shown to harbor BDV proteins although there did not appear to be a loss of these cells (Bautista et al, 1995). Reactive astrocytosis was detected with the use of antibodies against glial fibrillary acidic protein (GFAP) as early as 3 days post-infection (Bautista et al, 1995). Neuropathological sequalae of other viral infections can result in loss of Purkinje cells, either as a direct consequence of the infection in that cell type or as a secondary consequence of the loss of other cell types (Monjan et al, 1973). For example, viruses such as reovirus (Margolis et al, 1971) and lymphocytic choriomeningitis virus (Monjan et al, 1971) have been shown to produce cerebellar pathology including loss of Purkinje cells. Other, non-viral, insults such as traumatic brain injury (Fukada et al, 1996), lithium toxicity (Grignon and Bruguerolle, 1996) and autoimmunity associated with neoplasms (Jaeckle et al, 1985) have also demonstrated the vulnerability of Purkinje cells. Considering this vulnerability and the presence of BDV proteins within Purkinje cells we decided to reinvestigate the Purkinje cells in adult rats subjected to neonatal BDV infection.

\section{Results}

\section{Behavior}

No overt neurological symptoms were observed at the time of sacrifice ( 7 months). In general the rats displayed an increased degree of jitteriness and were highly responsive to touch and loud noises but did not display overt ataxia or myoclonic seizures.

\section{Gross cerebellar morphology}

The cerebellum of infected animals (sacrificed at 7 months of age) was reduced in size (Figure 1). There was a reduction in both the antero-posterior and medio-lateral dimensions of the cerebellum (Figure 1). This was not quantified. The normal foliation was present but each folium was smaller.

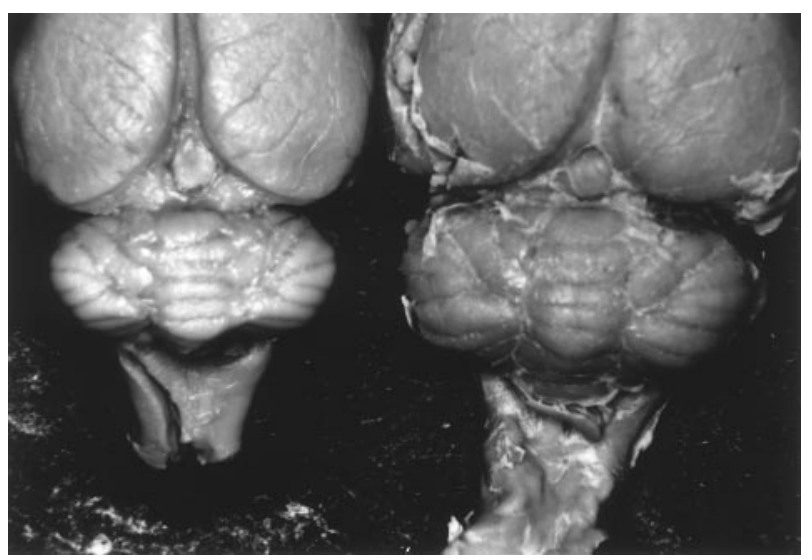

Figure 1 Photograph of a BDV infected and an uninfected (CONT) rat brain. Notice the smaller size of the BDV infected brain (on the left). In particular the cerebellum (Cb) is much reduced in size. Bar $=1 \mathrm{~mm}$. 
Histological analysis

Sections stained with cresyl violet revealed that the cerebellar laminar organization seen in the control animals (Figure 2A) is also present in the BDV infected animals (Figure 2B). From the pial surface inward, the molecular, Purkinje cell and granular layers are present in both the control and BDV infected animals. At low magnification these layers look relatively normal, especially the molecular and granular layers (Figure 2). It is also clear that the folial pattern in the control and BDV animal, as seen in parasagittal sections, is almost identical (Figure 2). However, within the Purkinje cell layer, which normally forms a continuous monolayer of large perikarya, there are numerous gaps where there is an absence of Purkinje cells. This reduction in the number of Purkinje cells is visible in enlarged Nissl stained photomicrographs
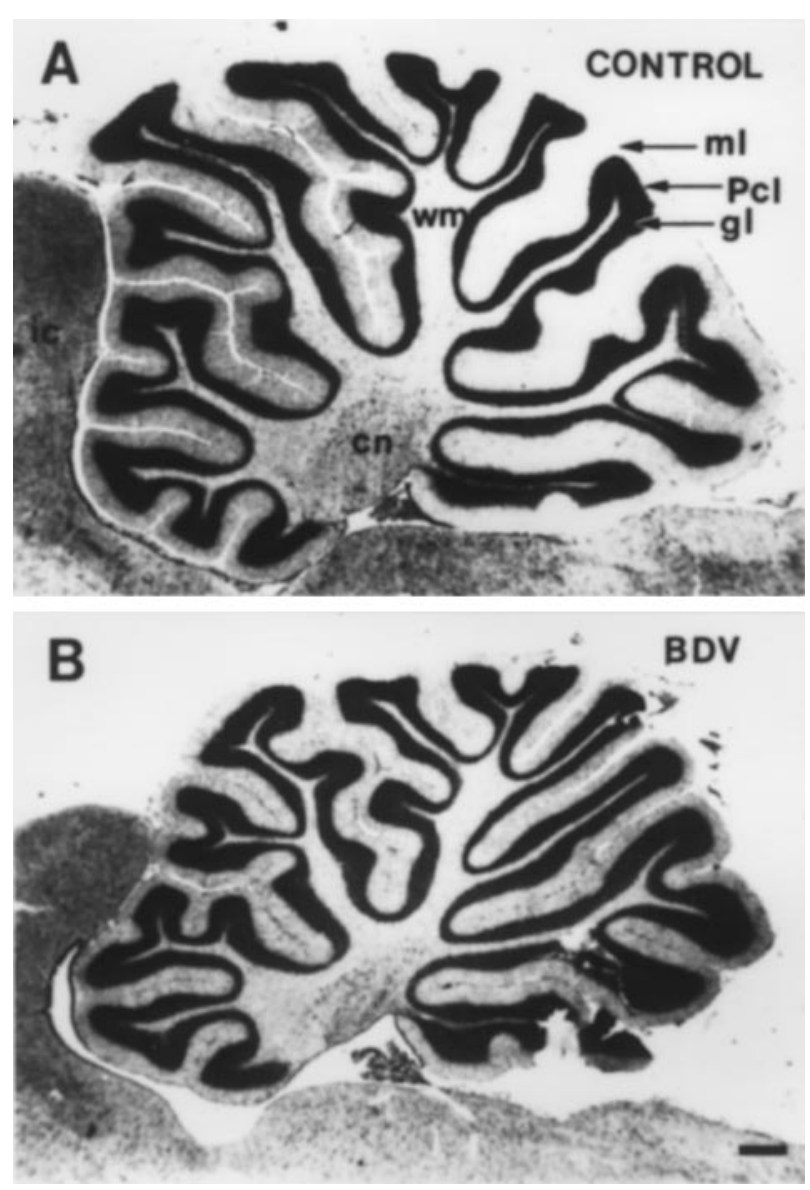

Figure 2 Photomicrographs of parasagittal sections of adult brains from an uninfected (CONT) and a neonatal infected BDV rat. Notice that the foliation and the cytoarchitectural lamination of the cerebella are very similar in both animals. In addition, there does not appear to be any obvious reduction in the thickness of the molecular $(\mathrm{ml})$ and/or granular layers (gl). cn=cerebellar nuclei, IC=inferior colliculus, Pcl=Purkinje cell layer, $\mathrm{wm}=$ white matter. $\mathrm{Bar}=280 \mu \mathrm{m}$.
(Figure 3) and is even more readily apparent in both coronal and parasagittal sections immunoreacted for the Purkinje cell-specific antigen, calbindin (Figure 4). In contrast to the even distribution of Purkinje cells seen in the control animal there are gaps in the staining of immunoreactive somata in the BDV infected animals. In addition, there are also gaps in the immunostaining of the dendritic trees of the Purkinje cells within the molecular layer. In the uninfected animal there is uniform staining of the molecular layer (Figures 4A, B and 5A, B) whereas in the BDV infected animal this immunoreactivity is patchy with immunonegative areas intervening between immunoreactive areas (Figures 4C, D and 5C, D). These qualitative analyses clearly suggested that there was a reduction in the number of Purkinje cells in the BDV infected animals.

Quantitation of Purkinje cells

We obtained an estimate of the difference in the number of Purkinje cells between neonatally BDV infected and control animals by counting the number of anti-calbindin immunoreacted cells in six similar parasagittal sections from each uninfected $(n=2)$ and infected $(n=5)$ animal. We did not correct the quantitative results for changes in cerebellar size as this would have only increased the differences observed, since BDV infected brains are smaller. The intent was to determine the difference in the number of PC in six parasagittal sections from each animal as an estimate of the total difference in Purkinje cell number. A count of PC in six sections in each animal was obtained and this was used to determine a mean for the BDV infected $(n=6)$ versus $(n=2)$ animals. The mean number of PC in the six sections in the BDV infected rats was 1308 or $25.5 \%$ of the mean number of PC (5128) in the six sections in control rats (Figure 6, Table 1). Thus, there was an approximately $75 \%$ loss of PC $(P<.001$ by the $t$-test) in adult rats neonatally infected with BDV. The distribution of immunoreactive Purkinje cells is somewhat variable. Some lobules appear to contain a fairly uniform complement of Purkinje cells whereas other lobules appear to be mildly or severely deficient in Purkinje cells (see Figure 4D). Although no attempt was made to quantitate the number of granule cells, the thickness of this layer in the BDV-infected rats appears to be similar to the control rats. However, since the cerebella of the infected rats was smaller overall, one would anticipate a reduction in the total number of granule cells.

\section{$B D V$ immunoreactivity}

Immunoreactivity was associated with most surviving Purkinje cells when sections are stained with a monoclonal antibody against the BDV protein p38 (Figure 7). Somewhat more 

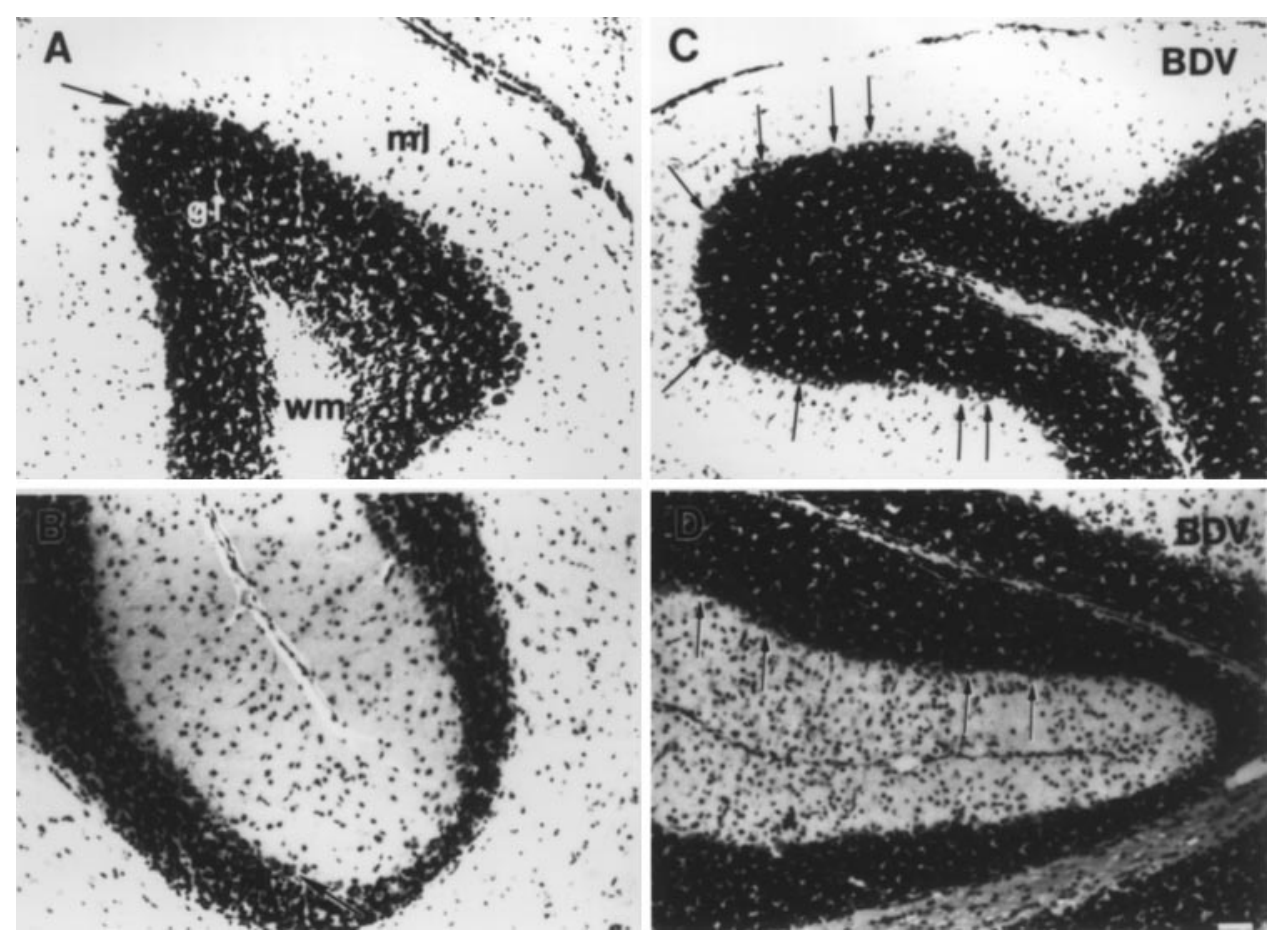

Figure 3 Photomicrographs of cresyl violet stained coronal (A and C) and sagittal (B and D) sections through the cerebellum of uninfected rat (A and $\mathbf{B}$ ) and neonatally BDV infected (C and $\mathbf{D})$ rat. Note that in the control rat cerebellum there is a continuous monolayer of Purkinje cells (arrows in $\mathbf{A}$ and $\mathbf{B}$ ) at the interface between the molecular (ml) and granular layers (gl). In the BDV infected animal (C and D) this monolayer is interupted such that only a few Purkinje cells are present (arrows). wm-white matter. Bar $=45 \mu \mathrm{m}$
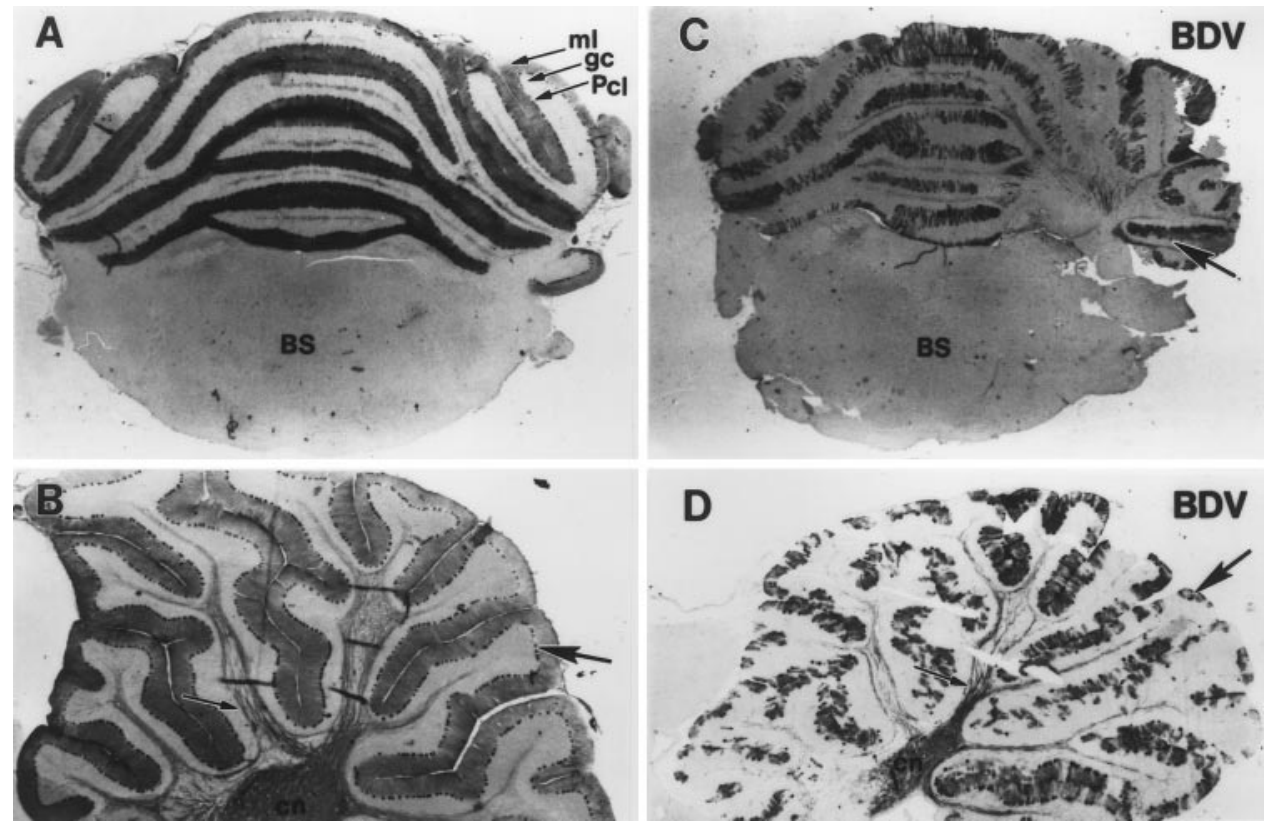

Figure 4 Coronal and sagittal sections through the adult brains of control (A and B) and neonatally BDV infected (C and D) rats immunostained for the Purkinje cell-specific antigen, calbindin. In the sections from the uninfected rats (A and B) notice the uniform monolayer of immunopositive Purkinje cells (arrow in B) and the uniform staining of the more superficial molecular layer (ml) which contains the Purkinje cell dendrites. In the neonatally BDV infected cerebella (C and D) the immunostaining of Purkinje cell monolayer (large arrows in $\mathbf{C}$ and $\mathbf{D}$ ) is interrupted by immunonegative spaces, indicating the absence of Purkinje cells. In addition, the immunostaining in the molecular layer also suggests areas devoid of Purkinje cell dendrites. The small arrows in $\mathbf{B}$ and $\mathbf{D}$ indicate the immunoreactive Purkinje cell axons which are projecting to the cerebellar nuclei (cn). BS=brainstem, Pcl=Purkinje cell layer. $\mathrm{Bar}=280 \mu \mathrm{m}$. 

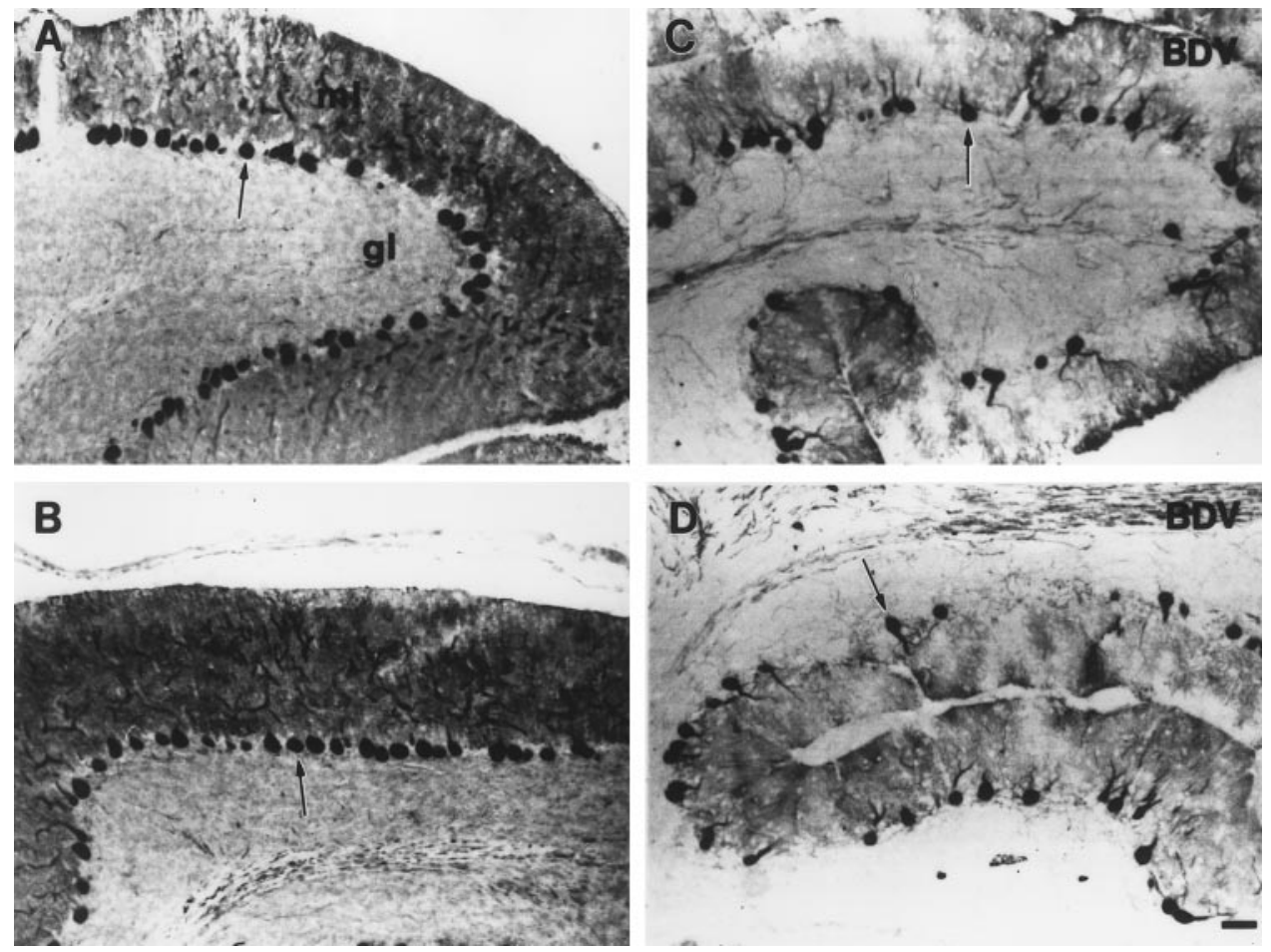

Figure 5 Higher power photomicrographs of sections through the cerebella of adult uninfected (A and B) and neonatally BDV infected rats immunostained with an antibody against calbindin. This antibody is Purkinje cell specific within the cerebellum. Small arrows indicate immunopositive Purkinje cells which form a monolayer of cells between the molecular layer (ml) and the granular layer (gl). Notice that relative to $\mathbf{A}$ and $\mathbf{B}$ there are numerous immunonegative spaces between these immunoreactive cells in $\mathbf{C}$ and $\mathbf{D}$, indicting a loss of Purkinje cells. Bar $=50 \mu \mathrm{m}$.

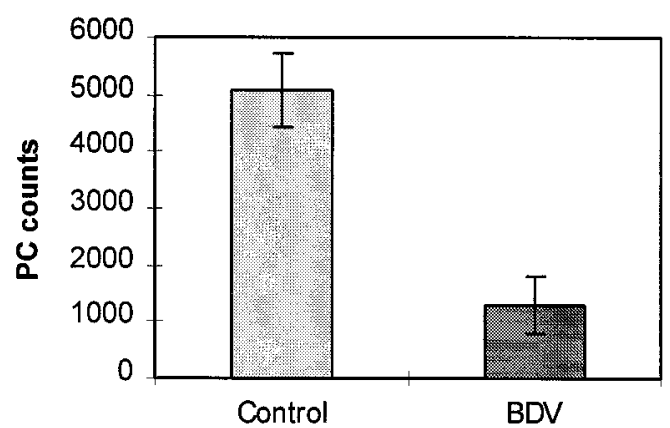

Figure 6 Bar graph illustrating the number of Purkinje cells counted in six similar parasagittal sections through the cerebella of uninfected $(n=2)$ and neonatally BDV infected $(n=5)$ rats. There is an approximately $75 \%$ reduction in the number of Purkinje cells in the BDV animals.

intense immunoreactivity could be seen within the nuclei of the Purkinje cells. Purkinje cells in control animals do not exhibit staining above background levels (Figure 7C). The other cellular constituents of the cerebellum are immunonegative except for an unidentified population of small cells sparsely distributed within the granular layer (Figure 7).
Table 1 Purkinje cell (PC) counts

\begin{tabular}{lcc}
\hline No. & Control & BDV \\
\hline 1 & 4621 & 1845 \\
2 & 5536 & 1311 \\
3 & - & 751 \\
4 & - & 837 \\
5 & - & 1779 \\
mean \pm s.d. & $5079 \pm 647$ & $1305 \pm 510$ \\
\hline
\end{tabular}

Significance of the differences between control and BDV infected mean PC counts is $P<.001$ by the $t$-test.

\section{Discussion}

The results of this study clearly demonstate that neonatal rats experimentally innoculated with BDV and examined at maturity, demonstrate a reduced cerebellar size and a significant loss of PC. This loss of PC is distributed throughout the cerebellum and results in empty spaces along the PC monolayer. Because of the reduced size of the cerebellum granule cells must also be reduced even though the thickness of the granular layer in sectioned material 

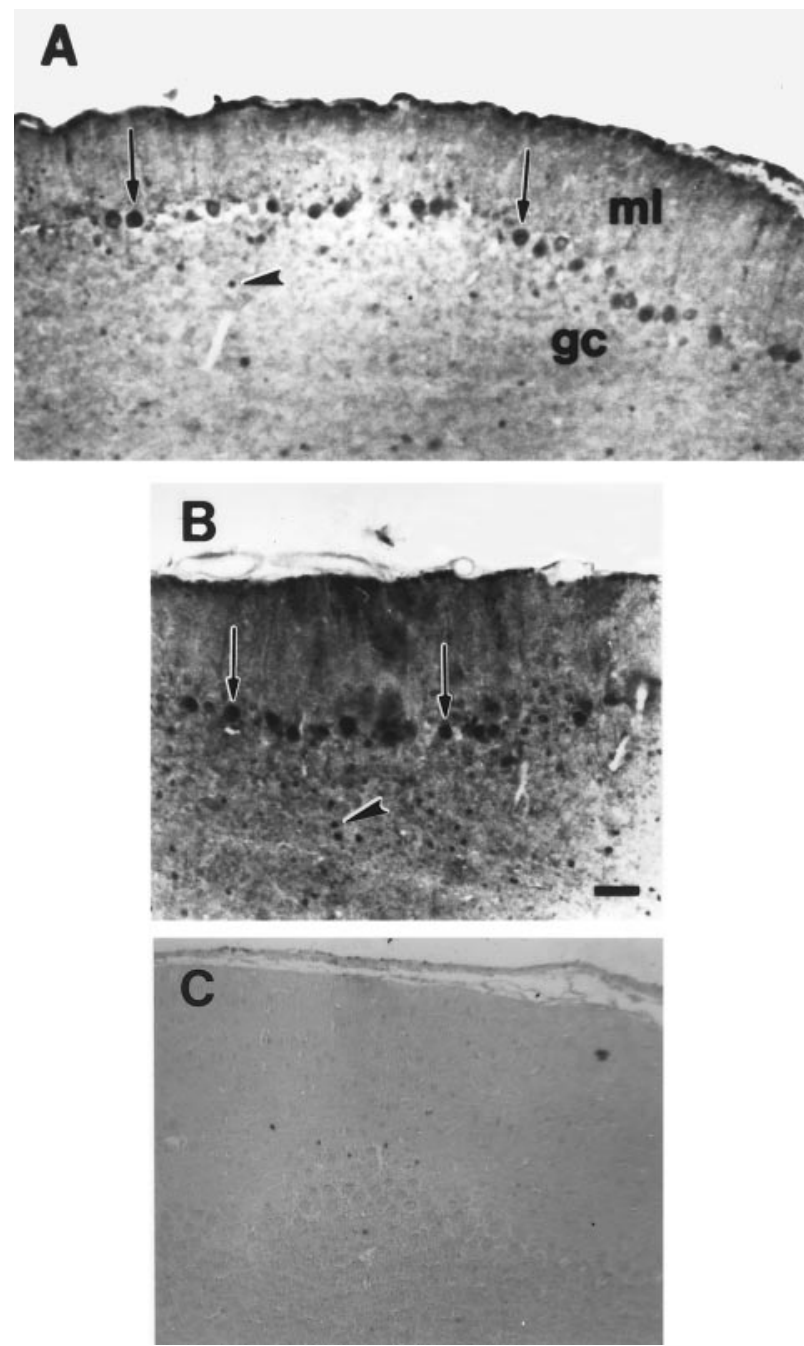

Figure 7 Photomicrographs of sections (A and $\mathbf{B}$ ) of cerebellum of neonatally BDV infected and control (C) rats immunoreacted with a monoclonal antibody against BDV protein. (A and $\mathbf{B}$ ) Notice that the immunoreactivity is restricted to Purkinje cells (arrows) and to an unidentified population of scattered small cells (arrowheads) within the granular layer (gl). In the Purkinje cells the immunoreactivity appears to be more intense within the nucleus and nuclear membrane of these cells. (C) In the control rat the immunoreactivity is PC and other cell types is not above background. gc=granular cells. Bar $=75 \mu \mathrm{m}$.

does not appear much different from that seen in the uninfected animal. Thus, the reduced size of the cerebellum is due to a large loss of Purkinje cells and a secondary loss of granule cells, their presynaptic partners. Purkinje cells and their elaborate dendrites, and massive number of granule cells account for most of the mass of the normal cerebellum. Reduction in these cell populations will therefore reduce the overall size of the cerebellum as seen in the neonatally BDV infected animals.

These results are somewhat different from those obtained in a developmental analysis of neonatal

BDV infection in rats done by Bautista et al (1995). Their analysis of animals at different ages postinjection, up to postnatal day 30 demonstrated a reduction in size of the cerebellum. This reduced size could not be accounted for by postweaning malnutrition. Their data also suggested a premature loss of the external granular layer, the germinal layer which gives rise to granule cells. A consequence of this was a reduction in the area of the molecular and internal granular layer (igl) as measured together, and of the igl as measured independently. This is consistent with our finding of a smaller cerebellum in the BDV infected animals. A smaller cerebellum would contain fewer granule cells unless proportionately more of the cerebellum was taken up by granule cells. This is clearly not the case. Although we did not measure the igl, we did not see any obvious decrease in the thickness of the igl (Figures 2 and 3), so the reduced area of granule cell layer could be simply due to a smaller cerebellum.

Our data are in agreement with Bautista et al (1995) concerning the presence of the BDV protein in most surviving PC (Figure 7). They reported these cells to be the only cerebellar cells that are immunoreactive to the anti-BDV antibody. Our data indicate there is also immunoreactivity in an unidentified small cell population which is scattered within the igl. Although it is not completely clear, it seems as though Figure 4 in their manuscript illustrates similar immunoreactive small cells in the igl.

More significantly, Bautista B et al. (1995) report that there was no loss of Purkinje cells in BDV infected neonatal Lewis rats examined at various times up to 30 days post-infection. As reported above, this is in contrast to the approximately $75 \%$ loss of these cells in our BDV-infected rats. This discrepancy could be due to a number of factors: (1) method of experimental infection; (2) our use of PCspecific staining techniques leading to recognition of the loss; (3) different BDV strains or (4) the loss of PC could occur after P30, the latest timepoint analyzed in their study. Whatever, the reason, it is very clear that in our experimental model of neonatal BDV infection in Lewis rats, there is significant loss of PC. In this context it is important to point out that all PC are generated during embryonic days 13-15, well before the time of infection in these studies. This might suggest that the developmental model in which BDV interferes with cell genesis and/or 'luxury functions' of PC may be premature (Bautista et al, 1995). Instead, neonatal BDV infection may either (1) target the PC and cause the death of these cells directly or (2) act indirectly by stimulating an immune response which is then responsible for the loss of these cells. It is known that PC are sensitive to immunological attack (Graus et al, 1988; Jaeckle et al, 1985; Rodriquez et al, 1988). Thus, the loss of PC after 
neonatal BDV infection may suggest that tolerance of BDV antigens in these rats may not be complete or that tolerance of BDV antigen diminishes as the animals age. A more complete analysis of the temporal aspects of PC loss after infection will address these possibilities.

With regard to the functional consequences of such a dramatic loss of Purkinje cells it is most interesting that these neonatally infected rats do not exhibit an obvious ataxia. Severe loss of Purkinje cells during the first postnatal month is often associated with motor ataxia in neurological mutant mice (Goldowitz and Eisenman, 1992). The fact that these rats do not exhibit an obvious ataxia suggests the loss of Purkinje cells is not immediate and/or occurs over a protracted period of time. Late onset and protracted Purkinje cell loss could permit the development of compensatory mechanisms to be established and thus motor ataxia may not develop or may not be that visible without specific testing.

\section{Materials and methods}

\section{$B D V$ injections}

One- to two-day-old Lewis rats were injected intracranially with $20 \mu \mathrm{l}$ of a 1/10 dilution of BDV virus infected rat brain homogenate (crude brain emulsion). When the infected rats were 7 months of age they were given an overdose of Ketamine (80 mg/kg containing $10-20 \mathrm{mg} / \mathrm{kg}$ xylazine i.m.) and perfused transcardially with $100 \mathrm{ml}$ of phosphate buffered saline (PBS) containing $5 \mathrm{~g} / \mathrm{l}$ procaine and 20000 IU heparin. This was followed by $50 \mathrm{ml}$ PBS and then $200 \mathrm{ml}$ of Bouin's fixative. The brains were removed and postfixed for 10 days in $70 \%$ ethanol and then blocked and embedded in paraffin. Sections were cut at $10 \mu \mathrm{m}$ from the

\section{References}

Amsterdam JD, Winokur A, Dyson W, Herzog S, Gonzalez F, Rott R, Koprowski H (1985). Borna disease virus: A possible etiologic factor in human affective disorders? Arch Gen Psychiat 42: $1093-$ 1096.

Bautista JR, Rubin SA, Moran TH, Schwartz GJ, Carbone KM (1995). Developmental injury to the cerebellum following perinatal Borna disease virus infection. Dev Brain Res 90: $45-53$.

Bechter K, Herzog S, Schuttler RV (1992). Possible significance of Borna disease for humans. Neurol Psychiat Brain Res 1: 23-29.

Billingham RE, Brent L, Medawar PB (1953). Actively acquired tolerance of foreign cells. Nature 172: 603.

Bode L, Reigel S, Ludwig H, Amsterdam JD, Lange W, Koprowski H (1988). Borna diseases virus-specific antibodies in patients with HIV infection and with mental disorders. Lancet 2: 689. cerebellar blocks in either the coronal or sagittal plane. Sections were then stained with cresyl violet or immunohistochemically processed with antibodies against (1) calbindin, a Purkinje cell specific (within the cerebellum) calcium binding protein (LeGrand et al, 1983), or (2) a monoclonal anti-BDV antibody.

Standard immunohistochemical procedures were used (Sternberger, 1979). Appropriate positive and negative controls were also processed to determine the specificity of the immunoreactivity. Sections were deparaffinized, and hydrated through a series of graded alcohols to water. Sections were incubated with $10 \%$ normal horse serum (NHS) for overnight. After $3 \times 5$ min rinses in phosphate buffered saline PBS the sections were incubated in primary antiserum (diluted $1: 200$ in $10 \% \mathrm{NHS}$ ) overnight. After $3 \times 5 \mathrm{~min}$ rinses in PBS, the sections were incubated in the appropriate secondary antibody conjugated to horseradish peroxidase. After three rinses in PBS, the sections were reacted for HRP using diaminobenzidine as the chromagen to give a brown reaction product. The sections were then examined using light microscopy.

\section{Quantitation of Purkinje cells}

Six similar parasagittal sections stained with anticalbindin were selected from infected $(n=5)$ and uninfected $(n=2)$ rats and were used to estimate the number of Purkinje cells in these animals. In the cerebellum, anti-calbindin is Purkinje cell-specific thus facilitating quantitative analysis of this cell type within the cerebellum.

The experiments conducted in this study have been reviewed and approved by the Institutional Animal Care and Use Committee of Thomas Jefferson University.

Bode L, Zimmerman W, Ferszt R, Steinbach F, Ludwig H (1995). Borna Disease virus genome transcribed and expressed in psychiatric patients. Nature Med 1: $1232-1236$.

Bracke-Tolkmitt R, Linden A, Canavan AGM, Rockstroh R, Scholz E, Wessel K, Diener H-C (1989). The cerebellum contributes to mental skills. Behav Neurosci 103: $442-446$.

Burtles SS, Hooper DC (1990). The effect of neonatal tolerance to Bovine gamma globulin (BGG) on BGGreactive CD4+ T lymphocytes. Immunol 75: 311-317.

Carbone KM, Duchala CS, Griffin JW, Kincaid AL, Narayan O (1987). Pathogenesis of Borna disease in rats: evidence that intra-axonal spread is the major route for virus dissemination and the determinant for disease incubation. J Virol 61: 3431-3440. 
Carbone KM, Park SW, Rubin SA, Waltrip RW, Vogelsang GB (1991). Borna disease: association with a maturation defect in the cellular immune response. $J$ Virol 65: 6154-6164.

Daum I, Ackermann H, Schugens MM, Reimoid C, Dichgans J, Birbaumer N (1993). The cerebellum and cognitive functions in humans. Behav Neurosci 107: $411-419$.

de la Torre JC, Carbone KM, Lipkin WI (1990). Molecular characterization of the Borna disease agent. Virology 179: $853-856$.

Fukuda K, Aihara N, Sagar SM, Sharp FR, Pitts LH, Honkaniemi J, Noble LJ (1996). Purkinje cell vulnerability to mild traumatic brain injury. J Neurotrauma 13: $255-266$.

Goldowitz D, Eisenman LM (1992). Genetic mutations affecting murine cerebellar structure and function. In: Genetically Defined Animal Models of Neurobehavioural Dysfunctions. Driscoll P (ed), Birkhauser, Zurich, pp 66-88.

Graus F, Sesgurado OG, Tolosa E (1988). Selective concentration of anti-Purkinje cell antibody in the CSF of two patients with paraneoplastic cerebellar degeneration. Acta Neurol Scand 78: 210-213.

Grignon S, Bruguerolle B (1996). Cerebellar lithium toxicity: a review of recent literature and tentative pathophysiology. Therapie 51: 101-106.

Ivry R, Keele SW (1989). Timing functions of the cerebellum. J Cognitive Neurosci 1: 132-150.

Jaeckle KA, Graus F, Houghton AH, Cardon-Cardo C, Nielsen SL, Posner JB (1985). Autoimmune response of patients with paraneoplastic cerebellar degeneration to a Purkinje cell cytoplasmic protein antigen. Ann Neurol 18: $592-600$.

Kishi M, Nakaya T, Nakamura Y, Kakinuma M, Takahashi TA, Sekiguchi S, Uchikawa M, Takokoro K, Ikeda K, Ikuta K (1995a). Prevalence of Borna disease virus RNA in peripheral blood mononuclear cells from blood donors. Med Microbiol Immuno 184: $135-138$.

Kishi M, Nakaya T, Nakamura Y, Zhong Q, Ikeda K, Senjo M, Kakinuma M, Kato S, Ikuda K (1995b). Demonstration of human Borea disease virus RNA in human peripheral blood monocytes. FEBS Letts 364: $293-297$

Legrand C, Thomasset M, Parkes CO, MC Clavel CO, Rabie A (1983). Calcium-binding protein in the developing rat cerebellum. An immunohistochemical study. Cell Tissue Res 233: 389-403.

Leiner HC, Leiner AL, Dow RS (1989). Reappraising the cerebellum: What does the hindbrain contribute to the forebrain? Behav Neurosci 103: 998-1008.

Lipkin WI, Travis G, Carbone KM, Wilson M (1990). Isolation and characterization of cDNA clones encoding the Borna disease agent. Proc Natl Acad Sci USA 87: $4184-4188$.

Margolis G, Kilham L, Gonatas NK (1971). Retrovirus type 3 encephalitis: observations of virus-cell interactions in neural tissues. I. Light microscopic studies. Lab Invest 24: 91-100.

Monjan AA, Gilden DH, Cole GA, Nathanson N (1971). Cerebellar hypoplasia in neonatal rats caused by lymphocytic choriomeningitis virus. Science 171: $194-196$.
Monjan AA, Cole GA, Gilden DH, Nathanson N (1973). Pathogenesis of cerebellar hypoplasia produced by lymphocytic choriomeningitis virus infection at 4 days of age. J Neuropathol 32: 110-124.

Morimoto K, Hooper DC, Bornhorst A, Corrisdeo S, Fu ZF, Schafer MK-H, Koprowski H, Weihe E, Dietzschold B (1996). Intrinsic responses to Borna disease virus infection of the central nervous system. Proc Natl Acad Sci USA 93: 13345-13350.

Narayan O, Herzog S, Frese K, Scheefers H, Rott R (1983). Behavioral disease in rats caused by immunopathologic responses to persistent Borna virus in the brain. Science 220: 1401-1403.

Oakley GP (1986). Frequency of human cogenital malformations. Clin Perinatol 1386: 545-554.

Oster-Granite ML, Herndon RM (1986). The pathogenesis of parvovirus-induced cerebellar hypoplasias in the Syrian hamster, Mesocricetus auratus. Fluorescent antibody, foliation, cytoarchitectonic. Golgi and electron microscopic studies. J Comp Neurol 169: 481522.

Raine CS, Fields BN (1973). Reovirus type 3 encephalitis-a virologic and ultrastructural study. J Neuropathol Exp Neurol 32: 19-33.

Richt J, Stitz L, Deschl U, Frese K, Rott R (1990). Borna disease virus-induced meningoencephalomyelitis caused by a virus-specific CD4+ $\mathrm{T}$ cell mediated immune reaction. J Gen Virol 71: 2565-2573.

Rodriquez M, Truh LI, O’Neill BP, Lennon VA (1988). Autoimmune paraneoplastic cerebellar degeneration: Ultrastructural localization of antibody-binding sites in Purkinje cells. Neurology 38: 1380-1386.

Rott R, Herzog S, Fleischer B, Winokur A, Amsterdam JD, Dyson W, Koprowski H (1985). Detection of serum antibodies to Borna disease virus in patients with psychiatric disorders. Science 228: 1755-1756.

Rott R, Herzog S, Richt J, Stitz L (1988). Immunemediated pathogenesis of Borna disease. Zentralblatt fur Bacteriologie 270: 295-301.

Rott R, Herzog S, Bechter K, Frese K (1991). Borna disease, a possible hazard for man? Arch Virol 118: $143-149$

Seay AR, Griffin DE (1981). Effects of viral infections on the developing nervous system. In: Progress in Perinatal Neurology, Korbkin R and Guilleminault C (eds). Williams and Wilkins, Baltimore, pp 121-154.

Solbrig MV, Koob GF, Fallon JH, Reid S, Lipkin WI (1996a). Prefrontal cortex dysfunction in Borna disease virus (BDV)-infected rats. Biol Psychiatry 40: $629-636$

Solbrig MV, Koob GF, Joyce JN, Lipkin WI (1996b). A neural substrate of hyperactivity in borna disease: changes in brain dopamine receptors. Virology 222: $332-338$

Sternberger LA (1979). 'Immunocytochemistry', 2nd Ed., John Wiley, New York.

Stitz L, Soeder D, Deschl U, Frese K, Rott R (1989). Inhibition of immune-mediated menigoencephalitis in persistently Borna disease virus-infected rats by cyclosporine A. I Immunol 143: 4250-4256.

Stitz L, Dietzschold B, Carbone KM (1995). Immunopathogenesis of Borna disease. Curr Top Microbiol Immunol 190: 75-92. 
VandeWound S, Richt JA, Zink MC, Rott R, Nanayan O, Clements JE (1990). A Borna disease virus cDNA clone encoding a protein recognized by antibodies in humans with behavioural diseases. Science 250: $1273-1281$.
Waltrip RW, Buchanan RW, Summerfelt A, Brier A, Carpenter WT, Rubin SA, Carbone KM (1995). Borna disease virus and schizophrenia. Psychiatry Res 56: $33-44$. 